\title{
Un mot de la rédactrice
}

Je suis heureuse de présenter ce numéro spécial, pour lequel John M. LaVelle et Jill A. Chouinard ont été les rédacteurs invités. La formation en évaluation est au cœur de ce que nous faisons, ce que nous enseignons à l'université, ce que nous offrons dans des cours de formation et de perfectionnement ou lorsque que nous agissons à titre de mentor pour de nouveaux ou nouvelles collègues. En effet, le travail d'une évaluatrice ou d'un évaluateur vise souvent à sensibiliser diverses parties prenantes à la valeur, au processus et aux impacts de lévaluation. Chouinard et LaVelle ont rassemblé plusieurs personnes chargées de cours ou de formation en évaluation provenant d'horizons et de perspectives divers pour décrire la façon dont lévaluation peut être enseignée et apprise. Ce volume novateur est aussi le premier numéro de la RCEP à être entièrement composé de notes sur la pratique et il offre des idées et des leçons facilement transférables, desquelles notre communauté peut sans doute profiter. Je transmets mes remerciements aux auteurs et autrices de ces 15 textes qui ont bien voulu nous faire part de leurs réflexions, de leurs expériences et de leurs outils, ainsi qu’aux deux rédacteurs invités qui ont géré cet ambitieux projet. N'hésitez pas à nous communiquer les leçons que vous avez tirées de cette lecture et les façons dont vous avez mis en œuvre certaines de ces idées.

Isabelle Bourgeois

Rédactrice en chef 